\title{
GENE FLOW BET WEEN THREE EUCALYPT SPECIES AT SNUG PLAINS
}

\author{
by N.J. Davidson, J.B. Reid and B.M. Potts
}

(with two tables and eight text-figures)

DAVIDSON N.J., REID, J.B. \& POTTS B.M., 1987 (30:vi): Gene flow between three eucalypt species at Snug Plains. Pap. Proc. R. Soc. Tasm., 121: 101-108. https://doi.org/10.26749/rstpp.121.101 ISSN 0080-4703. Department of Botany, University of Tasmania, Hobart, Tasmania, Australia 7001.

The extent of hybridisation and gene flow between the three Monocalyptus species, Eucalyptus pulchella, E. coccifera (series Piperitae) and E. delegatensis (series Obliquae) at Snug Plains $(600 \mathrm{~m})$ in southeastern Tasmania was examined. The flowering time of E. pulchella was two months later than usual for this normally low-altitude species. It consequently overlapped the flowering period of both sub-alpine species $E$. coccifera and $E$. delegatensis and had its peak flowering period intermediate between the two. The movements of pollinators across the species boundaries indicated the potential for hybridisation between $E$. pulchella and the other two species.

Adult morphology suggested that the Snug Plains $E$. pulchella tended towards E. coccifera compared to typical, low-altitude $E$. pulchella and progeny tests reinforced this view. In addition, two out of twelve E. pulchella adults sampled appeared intermediate between this species and $E$. coccifera and produced progeny overlapping those from $E$. coccifera. These results suggest that introgression of E. coccifera genes may be occurring into E. pulchella at Snug Plains although adaptive convergence cannot be excluded. Quite a different picture is seen for the results of hybridisation between $E$. pulchella and $E$. delegatensis. Six putative $F_{1}$ hybrids between $E$. pulchella and $E$. delegatensis occurred in progeny from two E. pulchella mothers. However, this appears to have had little genetic impact on the species, since no evidence of introgression or convergence was apparent in adult populations of these species.

Key Words: gene flow, hybridisation, introgression, eucalypt species, Tasmania

\section{INTRODUCTION}

While genetic isolation appears to be maintained at the subgeneric level in the genus Eucalyptus, there are few absolute barriers to interbreeding between species within a subgenus although the extent of natural hybridisation varies considerably (Curtis \& Morris 1975, Pryor 1976). In Tasmania hybridisation between closely related species from the informal series Piperitae (subgenus Monocalyptus, Pryor \& Johnson 1971) is common (Potts \& Reid 1983, 1985a) with many recognised taxa exhibiting complete intergradation (e.g. Shaw et al. 1984). In contrast, despite frequent geographical contact between species from the series Piperitae and the series Obliquae (also subgenus Monocalyptus), there are only a few records of interseries hybrids (Pryor 1957a, Jackson 1958, Potts \& Reid 1983). In the present study we compare the extent of inter-series and intra-series hybridisation and gene flow between two Piperitae species ( $E$. pulchella Desf. and E. coccifera Hook. f.) and one Obliquae species (E. delegatensis R.T. Baker) at Snug Plains in southeastern Tasmania by examining the flowering phenology and adult and seedling morphology.

Snug Plains is one of the few areas where these three species can be found in parapatry and is unique since an extensive plateau occurs at an intermediate altitude (approx. $600 \mathrm{~m}$ ) near the upper and lower altitudinal limits respectively of the lowland (e.g. E. pulchella) and sub-alpine (e.g. E. coccifera and E. delegatensis) eucalypt floras. A complex mosaic of eucalypt species occurs on the plateau in response to microhabitat variations arising from the interaction of ecological factors such as frost, drought and water logging (Davidson \& Reid 1985, 1987, Davidson 1986).

\section{MATERIALS AND METHODS}

The study site was a shallow rocky ridge on the eastern side of Snug Plains at an altitude of $600 \mathrm{~m}$ (see Davidson \& Reid 1985 for details) where a small population of E. pulchella (200-500 mature trees) approximately $50 \mathrm{~m}$ wide followed the ridge crest for $0.5 \mathrm{~km}$ flanked by populations of $E$. coccifera to the west and $E$. delegatensis to the east. At this site herbarium samples of adult foliage (fig. 1) and fruit were collected from six trees of $E$. delegatensis and $E$. coccifera and two samples of six trees of $E$. pulchella. The first E. pulchella 


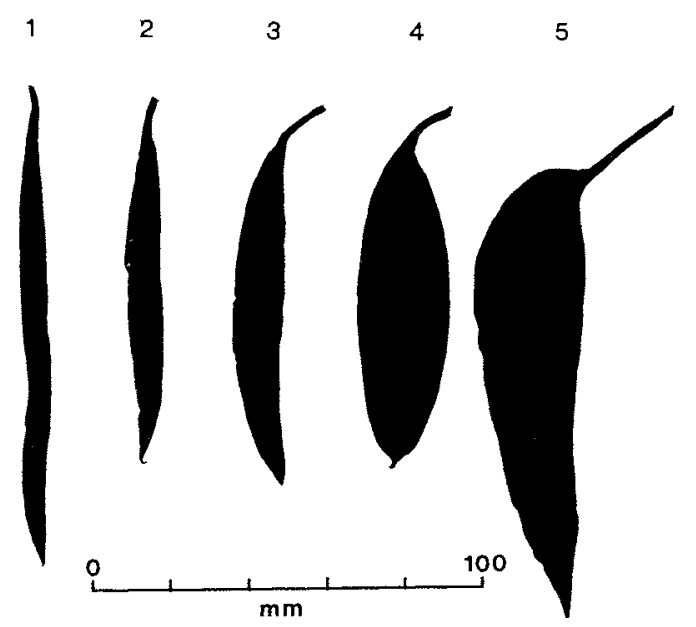

FIG.I - Typical adult leaves for lowland E. pulchella (I), Snug Plains E. pulchella from the ridge top (2) and a shallow depression (associated with E. coccifera) (3), Snug Plains E. coccifera (4), and Snug Plains E. delegatensis (5).

population came from a ridge top site where shallow soil occurred over dolerite bedrock, while the second came from a slight depression in the ridge crest with deeper soil in which adults of both $E$. pulchella and E. coccifera occurred (near stand D, fig. 2 in Davidson \& Reid 1985). A separate collection of herbarium specimens and fruit was also made for six trees from a lowland population of $E$. pulchella at a site $5 \mathrm{~km}$ east of the study area, at an altitude of approximately $100 \mathrm{~m}$. Six representative leaves and 20 capsules were selected from the material collected from each tree. A limited set of morphological characters was measured for the adult leaves and air-dry weights were obtained for the capsules. The leaf characters measured were a subset of those used by Potts \& Reid (1983) and were previously shown to be sufficient to discriminate between Monocalyptus species (Potts \& Reid 1983, 1985a). They included petiole length, leaf lamina length, leaf lamina width, length to widest point of the leaf, and basal asymmetry of the leaf (fig. 2). Statistical analysis of the adult leaf and fruit data set included analysis of variance and canonical variates analysis. Canonical variates analysis (Seal 1966) has been widely used in the study of hybridisation in Eucalyptus (e.g. Hopper et al. 1978, Potts \& Reid 1983).

Progeny trials were conducted for the five

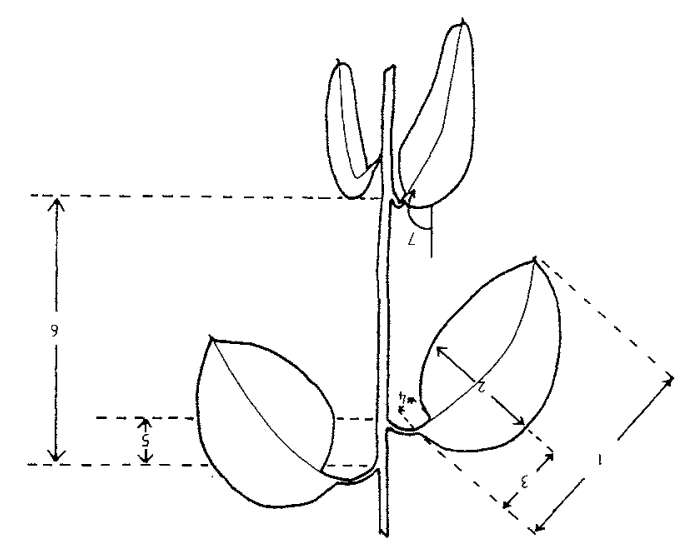

FIG.2 - Seven of the morphological characters measured from seedling leaves: $1=$ lamina length, 2 = lamina width, $3=$ length to widest point of the lamina, $4=$ basal asymmetry of the leaf, $5=$ intranode length, $6=$ internode length, and $7=$ leaf rotation (from the vertical).

populations sampled in the field [lowland $E$. pulchella, Snug Plains E. pulchella (two populations), Snug Plains E. coccifera, and Snug Plains $E$. delegatensis $]$. The seed, which was collected concurrently with the herbarium samples from six adult trees, was stratified for four weeks at $4^{\circ} \mathrm{C}$ in a cold room, then germinated on moist vermiculite and pricked out, at the cotyledonary stage, into plywood veneer tubes filled with potting soil. Ten replicate seedlings were planted for each tree (a total of 300 seedlings). The seedlings were arranged in a randomised block design, with an edge row in a glasshouse. The seedlings were watered three times weekly and nutrient was supplied via slow release fertilisers (Osmocote, blood and bone) present in the potting mix.

After four months growth a single leaf was removed from nodes 5, 7 and 10 of each seedling and a set of morphological characters measured for each leaf. The set of measurements made for the seedling leaves were the same as those measured for adult leaves a part from addition of measures of leaf glaucousness (scored on a 1 to 5 scale), lamina thickness and rotation of the leaf to the vertical [scored on a 1 (horizontal) to 4 (vertical) scale, fig. 2]. Where seedling leaves were sessile (e.g. $E$. coccifera) basal leaf width at the point of junction with the stem was measured. This measure was 
combined in one variable with petiole length by recording it as a negative distance, mutually exclusive to a positive petiole length (see Potts \& Reid 1985a). Internode length and intranode length were also measured at nodes 5, 7 and 10. Internode length was measured between the node at which the leaf characters were measured and the immediately preceding node. Analysis of variance and canonical variates analysis was performed on the above set of seedling morphological characters. The data for node 10 only are presented since essentially similar results were obtained from the analysis of data from each node.

The field populations of E. pulchella (ridge top population), E. coccifera and E. delegatensis at Snug Plains and the lowland population of $E$. pulchella were also assessed for time and intensity of flowering. The same random sample of thirty trees were visually assessed on each visit to each population. The sites were visited fortnightly between October 1981 and April 1982 and the intensity of flowering was scored on a 1 to 10 scale $(0=$ no open flowers) for each tree and a population mean determined.

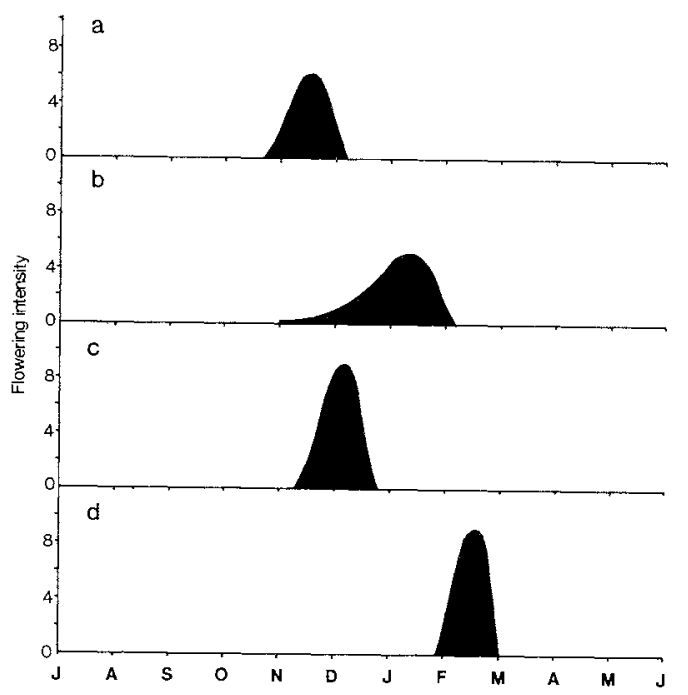

FIG.3 - Flowering time (month) versus intensity (on a 0 to 10 scale) during 1981-82 for: (a) lowland $\mathrm{E}$. pulchella, (b) the ridge top population of $\mathrm{E}$. pulchella at Snug Plains, (c) Snug Plains E. coccifera, and (d) Snug Plains E. delegatensis.

\section{RESULTS}

Flowering Time

The flowering time of the three Monocalyptus species present on Snug Plains $(600 \mathrm{~m})$, E. pulchella, E. coccifera and E. delegatensis, overlapped (fig. 3). The peak flowering time for typical Snug Plains $E$. pulchella from a ridge site was midway between the peaks for $E$. coccifera and $E$. delegatensis and showed a skewed distribution, starting at a low intensity before, and continuing throughout, the flowering period of E. coccifera. This indicated the potential for hybridisation exists between these three largely parapatric eucalypt species, although the probability of $E$. pulchella hybridising with $E$. coccifera or $E$. delegatensis would be much greater than hybridisation between $E$. coccifera and $E$. delegatensis. The peak flowering time for the Snug Plains E. pulchella was two months later than for E. pulchella from a nearby low altitude site $(100 \mathrm{~m})$ and the Snug Plains E. coccifera was more than a month earlier than normal for this species (Potts \& Reid 1983). Observations of the movements of New Holland honeyeaters (Phylidonyris novaehollandiae), yellow wattle birds (Anthochaera paradoxa) and a variety of pollinating insects which fed from flowers in the crown of each of the species at Snug Plains indicated that these pollinators move indiscriminantly across species boundaries during occasions when the flowering periods of the eucalypt species overlapped.

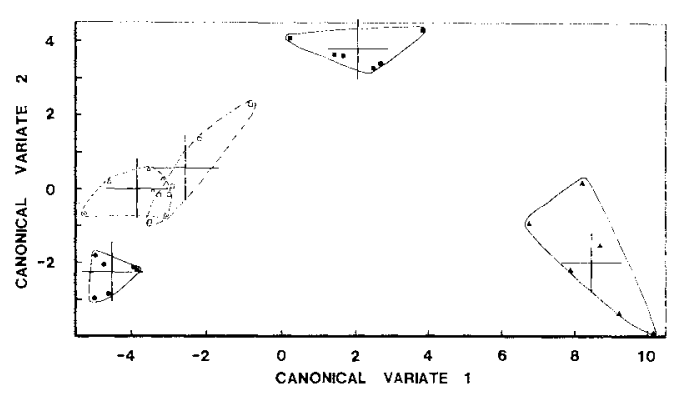

FIG.4 - Canonical variate 1 versus canonical variate 2 derived from an analysis of six morphometric characters measured on adult foliar and capsule material collected in the field for: lowland E. pulchella (•), Snug Plains E. pulchella from the ridge top $(\triangle)$, and shallow depression ( $\square$ ), Snug Plains E. coccifera ( $\mathbf{0})$, and Snug Plains E. delegatensis (४). Means are shown for each population. 


\section{TABLE 1}

\section{Adult Foliar and Capsule Parameters}

Mean ( \pm S.E.) leaf lamina length (LL), leaf lamina width (LW), length to the widest point of the leaf(LWP), petiole length (PL), basal asymmetry of the leaf (Basym), and capsule weight (Cap.wt.), measured for adult foliar and capsule material collection from lowland E. pulchella, Snug Plains E. pulchella from the ridge top and the shallow depression, E. coccifera and $E$. delegatensis. $\mathrm{n}=6$.

Species LL (mm) LW (mm) LWP (mm) PL (mm) Basym (mm) Cap.wt (g)

\begin{tabular}{lrrrrrr}
\hline E. pulchella (low) & $105.4 \pm 2.5$ & $6.36 \pm 0.09$ & $54.6 \pm 1.6$ & $6.59 \pm 0.18$ & $0.156 \pm 0.005$ & $0.053 \pm 0.002$ \\
E. pulchella (ridge top) & $79.4 \pm 1.3$ & $7.68 \pm 0.13$ & $42.4 \pm 0.5$ & $7.54 \pm 0.20$ & $0.144 \pm 0.010$ & $0.135 \pm 0.006$ \\
E. pulchella (depression) & $79.6 \pm 0.7$ & $9.15 \pm 0.44$ & $39.7 \pm 0.4$ & $10.17 \pm 0.54$ & $0.213 \pm 0.009$ & $0.170 \pm 0.014$ \\
E. coccifera & $84.1 \pm 1.5$ & $19.44 \pm 0.96$ & $35.3 \pm 0.9$ & $16.21 \pm 0.62$ & $0.383 \pm 0.097$ & $0.346 \pm 0.004$ \\
E. delegatensis & $111.9 \pm 2.0$ & $26.27 \pm 0.27$ & $29.8 \pm 0.8$ & $21.59 \pm 0.61$ & $6.839 \pm 0.379$ & $0.266 \pm 0.009$ \\
\hline
\end{tabular}

\section{Adult Morphology}

The five populations differed significantly ( $P$ $<0.001)$ for each of the six adult characters scored (table 1). The two populations of E. pulchella from Snug Plains were intermediate between the low altitude E. pulchella and the E. coccifera populations for all characters except lamina length and basal asymmetrv of the leaf.

Canonical variates analysis of the adult characters clearly separated the $E$. coccifera, $E$. delegatensis and low altitude $E$. pulchella populations (fig. 4). Canonical variate 1 (CV1) contained $81 \%$ of the variation and mainly separated $E$. delegatensis from the two Piperitae species and was dominated by a comparison between lamina length and length to the widest point of the leaf. Canonical variate 2 (CV2, $17 \%$ of variation) mainly discriminated between $E$. coccifera and $E$. pulchella populations based primarily on a comparison of capsule weight and lamina length. The high altitude
E. pulchella populations from Snug Plains were distinct from the low altitude $E$. pulchella population and tended in the direction of $E$. coccifera.

\section{Seedling Morphology}

Analysis of variance indicated significant differences $(P<0.001)$ between the five populations for all ten characters scored (e.g. table 2). Canonical variates analysis using the ten seedling characters clearly separated the progeny from the E. coccifera, $E$. delegatensis and low altitude $E$. pulchella populations (fig. 5). Canonical variate 1 contained $76 \%$ of the variation and discriminated E. delegatensis from the other populations based on petiole length and lamina length while canonical variate 2 ( $22 \%$ of variation) discriminated E. coccifera from the other populations and contrasted lamina width with lamina length and petiole length. The progeny from the two Snug Plains populations of $E$. pulchella were intermediate (figs 5 and 6) and

\section{TABLE 2}

\section{Juvenile Foliar Parameters}

Mean ( \pm S.E.) for log (lamina length/lamina width) (log LL/LW), petiole measure (PM) and basal asymmetry (Basym) for juvenile leaves of progeny from lowland $E$. pulchella $(\mathrm{n}=52)$, Snug Plains $E$. pulchella from the ridge top $(\mathrm{n}=57)$ and the shallow depression $(\mathrm{n}=55)$, E. coccifera $(\mathrm{n}=53)$ and $E$. delegatensis $(\mathrm{n}=51)$

\begin{tabular}{lcrc} 
Species & $\log \mathbf{L L} / \mathbf{L W}$ & PM (mm) & Basym (mm) \\
\hline E. pulchella (low) & $0.99 \pm 0.019$ & $-2.8 \pm 0.34$ & $0.00 \pm 0.000$ \\
E. pulchella (ridge top) & $0.73 \pm 0.022$ & $-5.1 \pm 0.63$ & $0.10 \pm 0.046$ \\
E. pulchella (depression) & $0.63 \pm 0.027$ & $-11.7 \pm 0.87$ & $0.03 \pm 0.021$ \\
E. coccifera & $0.12 \pm 0.010$ & $-28.1 \pm 0.53$ & $0.00 \pm 0.000$ \\
E. delegatensis & $0.22 \pm 0.008$ & $8.5 \pm 0.40$ & $4.02 \pm 0.245$ \\
\hline
\end{tabular}




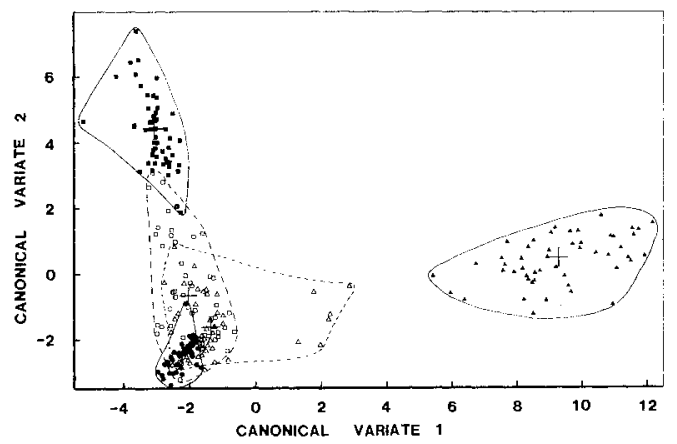

FIG.5 - Canonical variate I versus canonical variate 2 derived from an analysis of ten morphometric characters measured at the tenth node from glasshouse grown progeny of: lowland $\mathbf{E}$. pulchella (•), Snug Plains E. pulchella from the ridge top $(\Delta)$ and a shallow depression (associated with $\mathrm{E}$. coccifera) (ם), Snug Plains E. coccifera (ם), and Snug Plains E. delegatensis (४). Means are shown for each population.

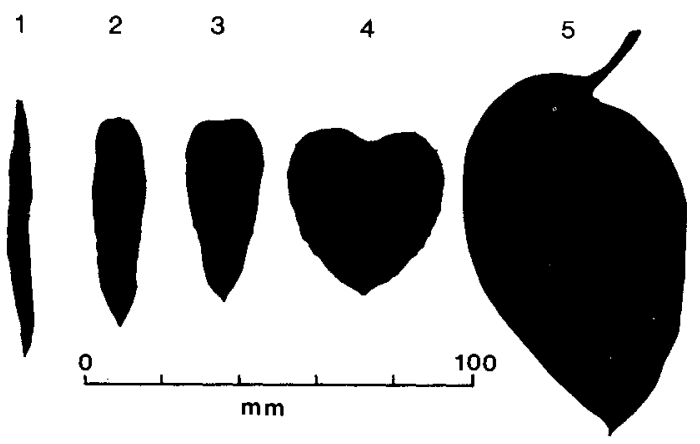

FIG.6 - Typical seedling leaves from progeny of lowland E. pulchella (1), Snug Plains E. pulchella from the ridge top (2) and a shallow depression (associated with E. coccifera) (3), Snug Plains E. coccifera (4), and Snug Plains E. delegatensis (5).

showed greater variability than the low altitude, allopatric E. pulchella population. However, in all but the progeny from one tree this increased variability seemed to be a result of interdependence of the variance and the mean on CV2 (fig. 7).

The two Snug Plains E. pulchella populations were significantly different (table 2 ). Both produced individuals overlapping the low altitude E. pulchella population and also individuals tending towards (a)

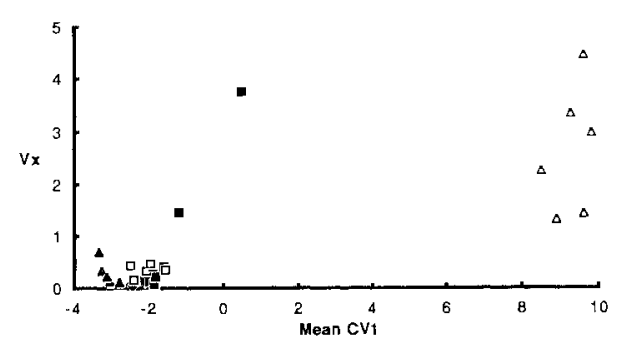

(b)

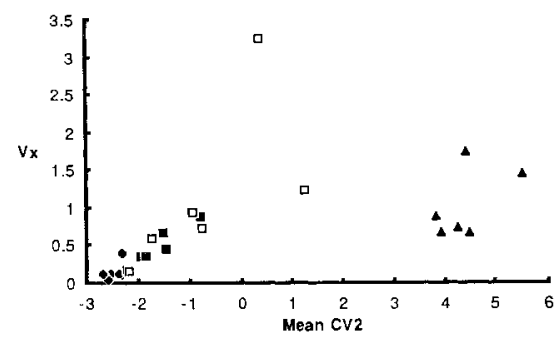

FIG.7 - The variance of CVI (a) and CV2 (b) scores (see fig. 5) plotted against the mean value for open pollinated progenies of lowland $\mathrm{E}$. pulchella $(\diamond)$, samples of E. pulchella from the ridge top ( $\square)$ and shallow depression (ए) on Snug Plains, E. coccifera $(\Delta)$ and E. delegatensis $(\Delta)$ from Snug Plains.

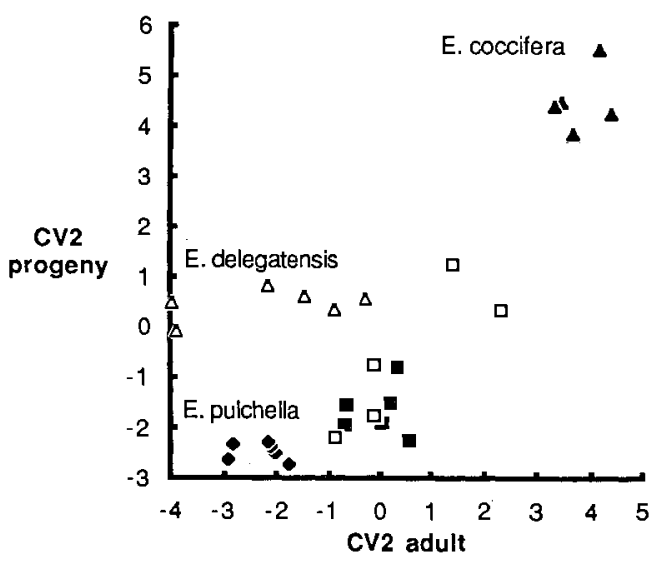

FIG.8 - The progeny mean score on CV2 (fig.5) plotted against the score of the maternal phenotype on CV2 from the analysis of adult morphology (fig. 4). Population symbols follow figure 7. 
the E.coccifera population (fig. 5). However, in the ridge top population two trees phenotypically identical in adult morphology to normal Snug Plains E. pulchella, produced six individuals (11\%) clearly separate from all other E. pulchella progeny and intermediate between typical progenies of $E$. pulchella and $E$. delegatensis as opposed to $E$. coccifera progeny (figs 5 and 6). Five of these intermediate types arose in progeny from a single E. pulchella tree and there can be little doubt these outliers a re a result of $F_{1}$ hybridisation between $E$. pulchella and $E$. delegatensis. The presence of these outliers had a marked effect on the variability of these two E. pulchella progenies which were clearly more variable for canonical variate 1 than were the progeny from the other four trees from the ridge top site (fig. 7). The Snug Plains E. pulchella population sampled from the shallow depression produced individuals showing continuous variation up to and overlapping the distribution of $E$. coccifera progeny (fig. 5). There was a high percentage (c. $22 \%$ ) of individuals in this population which, in this direction, lay beyond the range of $E$. pulchella progeny from the other Snug Plains population. The progeny overlapping the range of $E$. coccifera were mainly descended from the two parents in this population which were intermediate in adult morphology between $E$. pulchella and $E$. coccifera (fig. 8). However, the variability in open pollinated progeny from only one of these intermediates was greater than in other parental progenies (fig. 7 b).

\section{DISCUSSION}

The ecological preferences of E. pulchella, $E$. coccifera and $E$. delegatensis tend to result in spatial separation of these species. Direct genetic interaction is frequently restricted to boundary zones (e.g. E. coccifera and E. delegatensis) and only rarely do stands of $E$. pulchella occur with the two sub-alpine species (e.g. E. pulchella and $E$. coccifera on Middle Peak, Shaw et al. 1984). Prezygotic reproductive isolation is further accentuated by differences in flowering time. The flowering times are usually distinct with E. pulchella flowering before either of the other two species. In its "normal" ecological position E. pulchella has almost completed flowering before $E$. coccifera commences, while $E$. delegatensis flowers after $E$. coccifera (Potts \& Reid 1983). However, at Snug Plains all three species are parapatric and intermingle in boundary regions. E. pulchella flowers between the other two species and overlaps both. Together with the observed indiscriminate move- ment of pollinators these conditions clearly suggest the potential for pollen transfer between $E$. pulchella and the other two species at this site. The reversed flowering of E. coccifera and E. pulchella may be partly a consequence of populations of both species occurring at the upper and lower altitudinal extremes of their species range as flowering time has been reported to be delayed with increasing altitude in several eucalypt species (e.g. Barber \& Jackson 1957, Griffin 1980, Shaw et al. 1984).

Six progeny from two of the $E$. pulchella mothers from the ridge top population at Snug Plains (fig. 7a) were intermediate in phenotype between the $E$. pulchella and $E$. delegatensis seedlings (fig. 5) and are most likely $F_{1}$ hybrids between $E$. pulchella and E. delegatensis. They were intermediate not only in the characters scored but in all other observable characteristics. No such individuals were found in progeny from the $E$. delegatensis mothers sampled nor progeny from the other population of E. pulchella sampled on Snug Plains. This asymmetric hybridisation between $E$. pulchella and $E$. delegatensis could be due to several factors including the effect of flower size (Tibbits 1986) and the earlier flowering of the E. pulchella. The protandrous nature of eucalypt flowers (Pryor 1976, Griffin \& Hand 1979) would favour pollen of the later flowering species pollinating the earlier flowering species. A similar asymmetry has been noted between $E$. risdonii and $E$. amygdalina (Potts \& Reid 1985a, Potts 1986). The adult population samples from the study site at Snug Plains (fig. 4) showed no tendency for individuals intermediate between $E$. pulchella and $E$. delegatensis but in a widespread examination of the natural stands in the region a single localised hybrid swarm was discovered (saplings 4 to $6 \mathrm{~m}$ tall). This suggests that although hybridisation may occur between these species the $F_{1}$ individuals only occasionally survive to maturity and consequently there is probably little gene exchange between these species at Snug Plains.

A very different picture is found when examining the interaction between the two Piperitae species. In both adult (fig. 4) and progeny (fig. 5) morphology the Snug Plains E. pulchella trees tend towards $E$. coccifera in phenotype relative to the trees from the low altitude E. pulchella population. This occurs for reproductive as well as vegetative characters. Further, at least two adults from the Snug Plains E. pulchella population in the slight depression (associated with $E$. coccifera) are intermediate between the rest of this population and $E$. coccifera (fig. 8) and may well represent hybrids between these two species. Some of the offspring 
from these two trees overlap the distribution of the E. coccifera progeny (fig. 5). The lack of increased variability a mongst progeny from one of these two trees suggests advanced generation hybridisation (fig. 7b). Furthermore, with populations of $E$. pulchella at Snug Plains significantly different from lowland $E$. pulchella and tending in the direction of E. coccifera, there is the possibility that this divergence is a result of introgression of $E$. coccifera genes into the $E$. pulchella population and subsequent genetic stabilisation. Such introgression could be of adaptive significance since the reduced leaf lengths found in the Snug Plains $E$. pulchella populations may be less prone to wind and ice damage in the sub-alpine environment. $E$. coccifera genes may also confer increased frost resistance on the E. pulchella population (see Davidson \& Reid 1985). However, similar convergence of $E$. pulchella toward the E. coccifera phenotype could result from adaptive differentiation within $E$. pulchella since the direction of divergence (in several charauters) is similar to that noted to occur with altitude in other Eucalyptus species. For example, in many species leaf length is reduced (Pryor 1957b, Barber \& Jackson 1957, Phillips \& Reid 1980, Shaw et al. 1984, Potts \& Reid 1985b) and capsule size is increased (e.g. Phillips \& Reid 1980, Shaw et al. 1984) with increasing altitude. In either case, the presence of phenotypes similar to the low altitude E. pulchella in the seedling cohort (fig. 5), but the absence of overlap in the adult populations may reflect strong selection against low altitude $E$. pulchella types at Snug Plains although this remains to be verified.

The plateau at Snug Plains is environmentally heterogeneous, with slight topographic changes resulting in various areas exposed to severe frosts and waterlogging while other areas are subject to drought (Davidson \& Reid 1985, 1987; Davidson 1986). This results in a unique and complex mosaic of "typically" lowland and sub-alpine eucalypt species. Furthermore, with the intermediate altitude of the plateau it is conceivable that slight climatic changes may have a pronounced effect on its suitability as a habitat for lowland and sub-alpine eucalypt species. The introgression of $E$. coccifera genes into the E. pulchella gene pool may have allowed the lowland species, E. pulchella, to maintain a foothold in this largely sub-alpine region and avoid extinction. Adaptive introgressive hybridisation may genetically buffer a species against environment change, increasing evolutionary flexibility and allowing population stability in an unstable environment. Nevertheless, the genetic and evolutionary consequences of hybridisation may vary markedly and while the present study demonstrates active $F_{1}$ hybridisation between $E$. pulchella and $E$. delegatensis, this seems to have had little genetic impact.

\section{ACKNOWLEDGEMENTS}

We wish to thank Mr L. Johnson, Ms A. Kitchener, Ms G. Permyak off and Mr C. Raine for technical assistance.

\section{REFERENCES}

BARBER, H.N. \&"JACKSON, W.D., 1957: Natural selection in action in Eucalyptus. Nature (London), 179: 1267-1269.

CURTIS, W.M. \& MORRIS, D.I.,1975: THE STUDENT'S FLORA OF TASMANIA. PART 1 . Second edition. Government Printer, Hobart.

DAVIDSON, N.J., 1986: ECO-PHYSIOLOGICAL STUDIES OF SUBALPINE EUCALYPTS Unpubl. Ph.D. thesis, University of Tasmania.

DAVIDSON, N.J. \& REID, J.B.,1985: Frost as a factor influencing the growth and distribution of subalpine eucalypts. Aust. J. Bot., 33: 657-667.

DAVIDSON, N.J. \& REID, J.B., 1987: The influence of hardening and waterlogging on the frost resistance of subalpine eucalypts. Aust. J. Bot., 35: $91-101$.

GRIFFIN, A.R., 1980: Floral phenology of a stand of mountain ash (Eucalyptus regnans F. Muell.) in Gippsland, Victoria. Aust. J. Bot., 28: 393-404.

GRIFFIN, A.R. \& HAND, F.C., 1979: Post-anthesis development of flowers of Eucalyptus regnans and the timing of artificial pollination. Aust. For. Res., 9: 9-15.

JACKSON, W.D., 1958: Natural hybrids in eucalypts, Part 1. E. $\times$ taeniola $(=E$. salicifolia $\times E$. sieberiana). Pap. Proc. R. Soc. Tasm., 92: 141-146.

HOPPER, S.D., COATES, D.J. \& BURBIDGE, A.H., 1978: Natural hybridization and morphometric relationships between three mallee eucalypts in the Fitzgerald River National Park, W.A. Aust. J. Bot., 26: 3I9-333.

PHILLIPS, R.L. \& REID, J.B.,1980: Clinal variation between Eucalyptus viminalis Labill. and $E$ dalrympleana Maiden. Aust. J. Bot., 28: 329-342.

POTTS, B.M., 1986: The population dynamics and regeneration of a hybrid zone between Eucalyptus risdonii and E. amygdalina. Aust. J. Bot,, 34: 305-329.

POTTS, B.M. \& REID, J.B., 1983: Hybridization between Eucalyptus obliqua L'Herit. and E. pulchella Desf. Aust. J. Bot., 31: 211-229.

POTTS, B.M. \& REID, J.B., 1985a: Analysis of a hybrid swarm between Eucalyptus risdonii Hook. f. and E. amygdalina Labill. Aust. J. Bot., 33: 543-562. 
POTTS, B.M. \& REID, J.B., 1985b: Variation in the Eucalypius gunnii-archeri complex. I. Variation in the adult phenotype. Aust. J. Bot., 33: 337-359.

PRYOR, L.D., 1957a: Selecting and breeding for cold resistance in Eucalyptus. Silvae Genet. 6:98-109.

PRYOR, L.D., 1957b: Variation in snow gum (Eucalyptus pauciflora Sieb.). Proc. Linn. Soc. N.S.W., 8I: 299-305.

PRYOR, L.D., 1976: THE BIOLOGY OF EUCALYPTS. Edward Arnold, London.

PRYOR, L.D. \& JOHNSON, L.A.S., 1971: A CLASSIFICATION OF THE EUCALYPTS. Australian National University Press, Canberra.
SEAL, H.L., 1966: MULTIVARIATE STATISTICAL ANALYSIS FOR BIOLOGISTS. Methuen and Co., London.

SHAW, M.J., POTTS, B.M. \& REID, J.B., 1984: Variation within and between Eucalyptus nitida Hook. f. and Eucalyptus coccifera Hook. f. Aust. J. Bot., 32: 64 I-654.

TIBBITS, W.N., 1986: FROST RESISTANCE IN EUCALYPTUS NITENS (DEANE \& $M A I-$ $D E N)$ MAIDEN. Unpubl. Ph.D. thesis, University of Tasmania.

(accepted 23 March 1987) 